\title{
The New Approach of Expansion Baldwin-Aibassov's Rules for Ring-Closing Reaction for d-and f-elements Periodic Table of Elements
}

\author{
Aibassov Yerkin, Yemelyanova Valentina, Shakieva Tatyana, Bulenbaev Maxat and Blagikh Evgeniy \\ Research Institute of New Chemical Technologies and Materials, Kazakh National University Al-Farabi, Almaty 005012, Kazakhstan
}

\begin{abstract}
The authors have studied the effect of a magnetic field on Baldwin's rules. The authors have proposed a new mechanism that takes into account the effect of the angle and energy endo- or exo-cyclization. The authors propose to extend the rule Bouldwin not only for $\mathrm{sp}^{3}-\mathrm{sp}^{2}$ - and sp- orbits, but and for $\mathrm{d}^{1}-\mathrm{d}^{10}$ and $\mathrm{f}^{1}-\mathrm{f}^{14}$ elements of I-VIII of the Periodic table.
\end{abstract}

Key words: Magnetic field, mechanism of the Baldwin's rule, endo- or exo-cyclization.

\section{Introduction}

Recently, much attention is paid to finding new approaches to extend and modify Bouldina rules for the endo- or exo-cyclization in Bioorganic and Medicinal Chemistry. In this article the authors consider an important aspect of the influence of magnetic field on Baldwin's rule [1-11].

The goal to explore studied the effect of a magnetic field on Baldwin's rules; and to determine the relationship Baldwin-Aibassov's rules for ring-closing reaction for $\mathrm{d}$ - and f-elements Periodic Table of Elements.

\section{Theory}

In 1976, J.E. Baldwin formulated a set of rules/guidelines governing the ease of intramolecular ring-closing reaction. Baldwin used these rules to gain valuable insight into the role of stereoelectronic effects in organic reaction and predict the feasibility of these reactions in synthetic sequences. A few years later in 1983, J. D. Dunitz and co-workers demonstrated that there are favored trajectories for

Corresponding author: Aibassov Erkin Zhakenovich, professor, research field: metal organic chemistry of uranium and thorium, $\mathrm{As}, \mathrm{Sb}$ and $\mathrm{Bi}$. the approach of one reactant molecule toward another. The authors must note, however, that there is substantial limitation on these rules; a large number of examples are known for which they do not apply.

Baldwin discovered that orbital overlap requirements for the formation of bonds favour only certain combinations of ring size and the exo/endo/dig/trig/tet parameters. Interactive 3D models of several of these transition states can be seen here (javascript required).

There are sometimes exceptions to Baldwin's rules. For example, cations often disobey Baldwin's rules, as do reactions in which a third-row atom is included in the ring.

Table 2 shows the Baldwin dis/favoured ring closures.

The rules apply when the nucleophile can attack the bond in question in an ideal angle. These angles are $180^{\circ}$ (Walden inversion) for exo-tet reactions, $109^{\circ}$ (Bürgi-Dunitz angle) for exo-trig reaction and $120^{\circ}$ for endo-dig reactions. Angles for nucleophilic attack on alkynes were reviewed and redefined recently. The "acute angle" of attack postulated by Baldwin was replaced with a trajectory similar to the Bürgi-Dunitz angle [4-11]. 

f-elements Periodic Table of Elements

Table 1 Shows of the most important ring closures: $(F=$ favored, $D=$ disfavored).

\begin{tabular}{lllllll}
\hline Ring size & Exo-dig & Exo-trig & Exo-tet & Endo-dig & Endo-trig & Endo-tet \\
\hline 3 & D & F & F & F & D & - \\
4 & D & F & F & F & D & - \\
5 & F & F & F & F & D & D \\
6 & F & F & F & F & F & D \\
7 & F & F & F & F & F & - \\
\hline
\end{tabular}

Some examples of exo- and endo-cyclization:

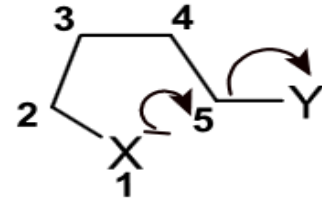

5-exo-tet<smiles>CCCCC1CCCCC1C</smiles>

6-endo-trig

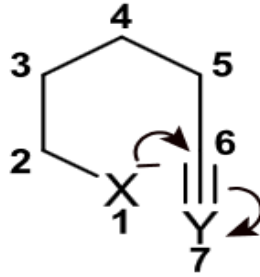

6-exo-dig

Walden

Tetragonal

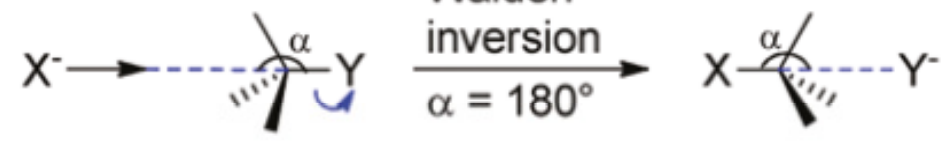

Trigonal
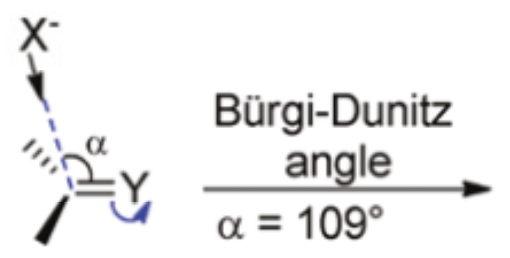<smiles>[Y]C1([X])C(C)(C)C1(C)C</smiles>

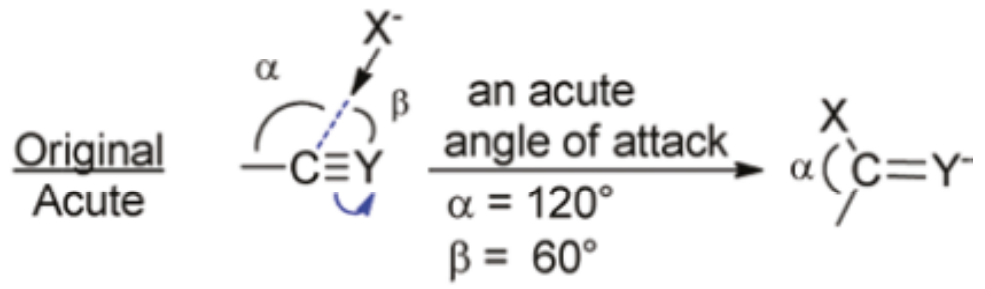

Digonal

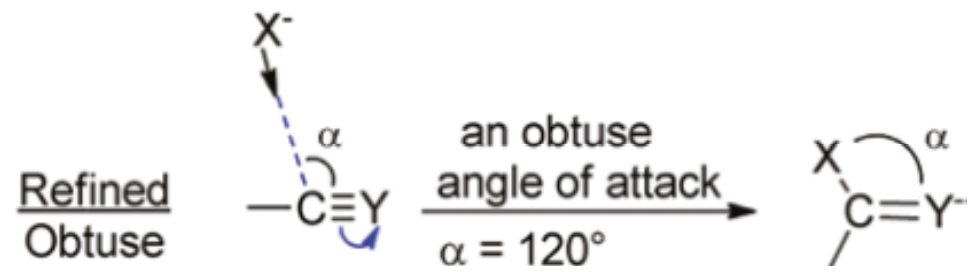

Table 2 Baldwin dis/favoured ring closures.

\begin{tabular}{|c|c|c|c|c|c|c|c|c|c|c|}
\hline & & 3 & & 4 & & 5 & & 6 & & 7 \\
\hline type & exo & endo & exo & endo & exo & endo & exo & endo & exo & endo \\
\hline tet & $\checkmark$ & & $\checkmark$ & & $\checkmark$ & $x$ & $\checkmark$ & $x$ & $\checkmark$ & $x$ \\
\hline trig & $\checkmark$ & $x$ & $\checkmark$ & $x$ & $\checkmark$ & $x$ & $\checkmark$ & $\checkmark$ & $\checkmark$ & $\checkmark$ \\
\hline dig & $x$ & $\checkmark$ & $x$ & $\checkmark$ & $\checkmark$ & $\checkmark$ & $\checkmark$ & $\checkmark$ & $\checkmark$ & $\checkmark$ \\
\hline
\end{tabular}


Table 3 Characteristic of some heteroazols.

\begin{tabular}{llll}
\hline Formula & Pyrrole & Phosphole & Arsole \\
\hline Configuration E & Planar & Pyramid & Pyramid \\
Electronic couple E & Part 6 $\pi$ e-system & Lone & Lone \\
Nature of the cycle & Aromatic & Dien & Dien \\
Enantiomers & No & No & Yes \\
\hline
\end{tabular}

\section{Results and Discussion}

Can you use a rule Bouldina for d- and f-elements in the periodic system of elements?

For example, consider the synthesis of biologically active organic compounds of Group V phosphorus, arsenic, antimony and bismuth. Heteroarenes $\mathrm{C}_{5} \mathrm{H}_{5} \mathrm{E}$ $(\mathrm{E}=\mathrm{N}, \mathrm{P}, \mathrm{As}, \mathrm{Sb}, \mathrm{Bi})$ were synthesized by reacting:

$$
\begin{aligned}
\mathrm{HC}= & \mathrm{C}-\mathrm{CH}_{2}-\mathrm{C}=\mathrm{CH}+\mathrm{n}-\mathrm{Bu}_{2} \mathrm{SnH}_{2} \rightarrow \mathrm{C}_{5} \mathrm{H}_{5} \mathrm{Sn}(\mathrm{n}-\mathrm{Bu})_{2} \\
& +\mathrm{ECl}_{3} \rightarrow \mathrm{C}_{5} \mathrm{H}_{5} \mathrm{E}-\mathrm{Cl}+\mathrm{DBU} \rightarrow \mathrm{C}_{5} \mathrm{H}_{5} \mathrm{E}
\end{aligned}
$$

where, $\mathrm{E}=\mathrm{N}, \mathrm{P}, \mathrm{As}, \mathrm{Sb}, \mathrm{Bi}$.

Heteroarenes Stability decreases in the order: $\mathrm{N}>$ $\mathrm{P}>\mathrm{As}>\mathrm{Sb}>\mathrm{Bi}$; arsabenzol stable stiba- and vismabenzoly, which quickly polymerize.

In phospholene and arsoli stabilization trigonalbipirimidalnogo condition occurs due to coupling. The data presented in Table 3 , indicate a decrease in participation $\mathrm{E}=\mathrm{C}$ interaction with increasing atomic number $\mathrm{E}$.

Thus, the table shows that the decline in the contribution of $\pi$-bond interactions in E-C is also observed during the transition from phosphorus to arsenic.

Cyclopentadienyl complexes of actinides prepared by reacting:

$$
\mathrm{AnCl}_{4}+4 \mathrm{KCp} \rightarrow \mathrm{Cp}_{4} \mathrm{An}+4 \mathrm{KCl}
$$

where $\mathrm{An}=\mathrm{Th}, \mathrm{U}, \mathrm{Np}$.

The authors suggested a simple and affordable methods for the synthesis of large series of new compounds, which will be used generally for Baldwin-Aibassov rule for ring-closing reaction for $\mathrm{d}$ and f-elements Periodic Table of Elements. These methods may be used when searching for new biologically active compounds.

\section{Conclusions}

Thus, the authors propose to extend and modify the rule for Baldwin exo- and endo-cyclization to d- and f-elements of the periodic table as well as the triple, double and single bonds, to mono- and poly-heterocyclic rings etc. heteroatomic.

The authors have proposed to take into account the rules Bouldina the formation of octahedra, flat, bipyramidal, tetrahedral configurations, etc.

The authors propose to extend the rule Baldwin not only for $\mathrm{sp}^{3}-, \mathrm{sp}^{2}$ - and $\mathrm{sp}$ - orbits, but and for $\mathrm{d}^{1}-\mathrm{d}^{10}$ and $\mathrm{f}^{1}-\mathrm{f}^{14}$ elements of I-VIII of the Periodic Table.

In the future, work will continue to use the modified rules Baldwin to form a (hetero) cycles with triple, double and single bonds, including for hetero atoms I-VIII of the Periodic Table.

This will expand the scope of use of the modified rules Baldwin important in the synthesis of biologically active substances.

\section{References}

[1] Baldwin, J. E. 1976. "Rules for Ring Closure.” J. Chem. Soc. Chem. 18: 734.

[2] Baldwin, J. E., Thomas, R. C., Kruse, L, I., and Silberman, L. 1978. "Rules for Ring Closure: Ring Formation by Conjugate Addition of Oxygen Nucleophiles.” J. Org. Chem. 42 (24): 3846.

[3] Gilmore, K., and Alabugin, I. V. 2011. "Cyclizations of Alkynes: Revisiting Baldwin's Rules for Ring Closure.” Chem. Rev. 111: 6513-56.

[4] Alabugin, I., Gilmore, K., and Manoharan, M. 2011. "Rules for Anionic and Radical Ring Closure of Alkynes." J. Am. Chem. Soc. 133: 12608-23.

[5] Li, X., Kyne, R. E., and Ovaska, T. V. 2007. "Synthesis of Seven-Membered Carbocyclic Rings via a Microwave-Assisted Tandem Oxyanionic 5-exo dig Cyclization-Claisen Rearrangement Process." J. Org. Chem. 72: 6624. 
f-elements Periodic Table of Elements

[6] Lin, G. Y., Yang, C. Y., and Liu, R. S. 2007. "Gold-Catalyzed Synthesis of Bicyclo[4.3.0]nonadiene Derivatives via Tandem 6-endo-dig/Nazarov Cyclization of 1,6-Allenynes." J. Org. Chem. 72: 6753-7.

[7] Overhand, M., and Hecht, S. M. 1994. "A Concise Synthesis of the Antifungal Agent (+)-Preussin." Journal of Organic Chemistry 59 (17): 4721-2.

[8] Baldwin, J. E., and Kruse, L. I. 1977. "Rules for Ring Closure. Stereoelectronic Control in the Endocyclic Alkylation of Ketone Enolates." Journal of the Chemical
Society 7: 233.

[9] Baldwin, J. 1982. "Rules for Ring Closure: Application to Intramolecular Aldol Condensations in Polyketonic Substrates." Tetrahedron 38 (19): 2939.

[10] Baldwin, J. E., Cutting, J., Dupont, W., Kruse, L., Silberman, L., Thomas, R. C. 1976. Rules for Ring Closure. J. Chem. Soc., Chem. Commun., 736-8.

[11] Alabugin, I. V., and Gilmore, K. 2013. "Finding the Right Path: Baldwin "Rules for Ring Closure" and Stereoelectronic Control of Cyclizations.” Chem. Commun. 49: 11246-50. 